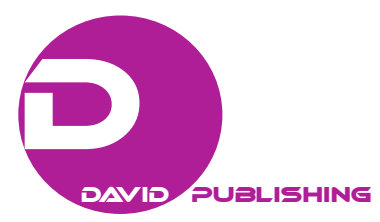

\title{
Econometric Investigation of DSE's Portfolios through Selective Micro and Macro Economic Indicators
}

\author{
Ahammad Hossain \\ PhD Fellow, Institute of Bangladesh Studies, University of Rajshahi, Bangladesh. E-mail: ahammadstatru@gmail.com \\ Md. Kamruzzaman \\ Associate Professor, Institute of Bangladesh Studies, University of Rajshahi, Bangladesh. E-mail: mkzaman.ru@gmail.com \\ Md. Ayub Ali \\ Professor, Department of Statistics, University of Rajshahi, Bangladesh. E-mail: ayubali67@yahoo.com
}

\begin{abstract}
This paper examines the impact of the portfolios of Dhaka Stock Exchange (DSE) with corresponding to the selective macro and micro economic indicators of Bangladesh. The microeconomic indicators are Invested Market Capital (IMC) (US\$) and the number of Total Enlisted Company (TEC) which have direct and immediate impact on the Stock Turnover Ratio (STR) of DSE and the macroeconomic indicators are Gross Domestic Product (GDP), Gross National Income (GNI), Gross Saving (GS), Gross Inflation (GI), Deposit Interest Rate (DIR), and Gross Foreign Investment (GFI) which have indirect and long run impact on DSE portfolios. To investigate the direct impact on DSE's turnover ratio, the Cobb-Douglas production function is applied and to investigate the indirect and long run impact, multiple linear regression models are also applied. The estimated results are diagnosed using magnitudes of derivatives, gradient and Wald's coefficient restriction with respect to the macro and micro economic indicators.
\end{abstract}

Keywords: Direct and immediate impact, Indirect and long run impact, magnitudes of derivatives, gradient and Wald's coefficient restriction

\section{Introduction}

Bangladesh is an emerging developing country in south Asia. Dhaka Stock Exchange (DSE) is one of the major capital markets, which plays an important role in mobilizing savings and investments for producing goods and services, creating employment opportunities, and enhancing sustainable economic growth of the country as a whole. But any sort of disorder of the microeconomic and macroeconomic indicators that may negatively influence on stock prices of the portfolios of capital market. Considerable amount of research literature can be found demonstrating the market volatility using univariate stock indicators models based on the relationship between stock market and macroeconomic variables. In the literatures, a number of studies are focused on the dynamic relationship of stock market with exchange rate and interest rate. Hossain, Kamruzzaman \& Ali (2015) studied the market volatility of DSE by proposing univariate ARIMA model on daily time based volume data. Modigliani (1971) and Mishkin (1977) proposed that lower interest rates raise stock prices which in turn to increase the capital investment. In general, a low interest rate leads higher assets flows to the stock market in expectation for a higher rate of return where a high interest rate encourages more savings in banks and thus 
reduces the flow of capital to the stock markets. Fama and Schwert (1977) studied the association between asset return and inflation. Akkas (2011) studied Bangladesh capital market instability from national macroeconomic management perspective under the global policy regimes of post-recession recovery. Hossain, Kamruzzaman \& Ali (2015) proposed vector autoregressive (VAR) models for the selected microeconomic indicators like stock market index, stock trade, invested market capital, stock volume of DSE for projection purposes. The present study is an endeavor to investigate the econometric impacts and consequences on DSE's portfolios with respect to the selective microeconomic and macroeconomic indicators. There are some microeconomic indicators like Invested Market Capital (IMC) (US\$) and the number of Total Enlisted Company (TEC) that influence the stock prices directly and some macroeconomic factors like Gross Domestic Product (GDP), Gross National Income (GNI), Gross Saving (GS), Gross Inflation (GI), Deposit Interest Rate (DIR), and Gross Foreign Investment (GFI) that also influence the stock prices indirectly in long run. The activities in the financial markets and their relationships with these microeconomic and macroeconomic factors have been explored significant impact to expose the financial risks along with efficient functioning the financial sector of the economy. The direct impact on DSE's turnover ratio is investigated by Cobb-Douglas production function (Cobb and Douglas, 1928)) and the long run impact is investigated by multiple linear regression model. The estimated results are diagnosed using magnitudes of derivatives, gradient and Wald's coefficient restriction with respect to the selective macro and micro economic indicators.

\section{Data Sources and Study Indicator's Basic}

This study is based on the secondary data. Secondary data like Invested Market Capital (IMC) (US \$) and the number of Total Enlisted Company (TEC), Stock Traded Turnover Ratio (STR), Gross Domestic Product (GDP), Gross National Income (GNI), Gross Saving (GS), Gross Inflation (GI), Deposit Interest Rate (DIR), and Gross Foreign Investment (GFI) were collected from the World Bank website and DSE General Index (DGI) (All share prices of A, B, G \& N categories of the portfolios of DSE) is collected from DSE website. (World Bank (2014), Dhaka Stock Exchange (2014))

\section{Invested Market Capital (IMC)}

Invested Market Capital is the total dollar market value of all of a company's outstanding shares. Market capitalization is calculated by multiplying a company's shares outstanding by the current market price of one share.

\section{Total Enlisted Company (TEC)}

Total Enlisted Company is the total number of companies that have the legal rights of trading of the companies' individual's portfolios in the stock market.

\section{Stock Traded Turnover Ratio (STR)}

Stock Traded Turnover ratio is the total value of shares traded during the period divided by the average market capitalization for the period. Average market capitalization is calculated as the average of the end-of-period values for the current period and the previous period.

\section{DSE General Index (DGI)}

DSE General Index is the closing price index of all share prices of A, B, G \& N categories with the respective market capital of the portfolios of DSE which is calculated as following: 


$$
\text { DSE General Index }(\text { DGI })=\frac{\text { Yesterday's Closing Index } \times \text { Closing Market Capital }}{\text { Opening Marker Capital }}
$$

\section{Gross Domestic Product (GDP)}

Gross domestic product is the monetary value of all the finished goods and services produced within a country's borders in a specific time period. It includes all private and public consumption, government outlays, investments and exports minus imports that occur within a defined territory. Gross domestic product can be calculated using the following formula: GDP $=\mathrm{C}+\mathrm{G}+\mathrm{I}+\mathrm{NX}$

Where, $\mathrm{C}$ is equal to all private consumption, or consumer spending, in a nation's economy, $\mathrm{G}$ is the sum of government spending, I is the sum of all the country's investment, including businesses capital expenditures and $\mathrm{NX}$ is the nation's total net exports, calculated as total exports minus total imports ( $\mathrm{NX}=$ Exports - Imports).

\section{Gross national income (GNI)}

Gross national income is GDP less net taxes on production and imports, less compensation of employees and property income payable to the rest of the world plus the corresponding items receivable from the rest of the world. An alternative approach to measuring GNI at market prices is as the aggregate value of the balances of gross primary incomes for all sectors.

\section{Gross Saving (GS)}

Gross saving is disposable income less consumption. It can be calculated for each institutional sector and the total economy.

\section{Gross Inflation (GI)}

Gross Inflation is the net rate at which the general level of prices for goods and services is rising and, consequently, the purchasing power of currency is falling. Central banks attempt to limit inflation, and avoid deflation, in order to keep the economy running smoothly.

\section{Deposit Interest Rate (DIR)}

The interest rate paid by financial institutions to deposit account holders. Deposit accounts include certificates of deposit, savings accounts and self-directed deposit retirement accounts.

\section{Gross Foreign Investment (GFI)}

Gross Foreign Investment is an investment made by the companies or entities based in one country, into the companies or entities based in another country.

\section{Methodology}

In economics, the Cobb-Douglas production functions is widely used to represent the relation-ship of an output to inputs. It was proposed by Knut Wicksell (1851-1926), and tested against statistical evidence by Charles Cobb and Paul Douglas in 1928. This function is nonlinear which is used in this study for modeling the stock turnover ratio estimation is of the form:

$$
Y=c L^{\alpha} K^{\beta}
$$

Where:

$Y=$ Total stock traded turnover ratio

$L=$ Total number of the enlisted companies 
$K=$ Total invested market capital

$c=$ Total factor turnover ratio

and $\alpha$ and $\beta$ are the stock traded turnover ratio elasticity's of total number of enlisted companies and total invested market capital, respectively. These values are constants. Taking log on both sides of equation (1), it becomes into simple log multiple linear regression model of the following form:

$$
\mathrm{LOG} Y=c+\alpha \mathrm{LOG} L+\beta \mathrm{LOG} K+\epsilon
$$

Where:

$$
\epsilon=\text { Random error term }
$$

The hypothesis of constant returns to scale is then tested by the restriction, $\alpha+\beta=1$.

To investigate the indirect and long run impact on DSE portfolios, Gross Domestic Product (GDP), Gross National Income (GNI), Gross Saving (GS), Gross Inflation (GI), Deposit Interest Rate (DIR), and Gross Foreign Investment (GFI) are considered as independent variables and DSE General Index (DGI) is considered as the dependent variable which can be expressed as the multiple log linear regression model of the following form:

$$
\mathrm{LOG}(\mathrm{DGI})=\alpha+\beta_{1} \mathrm{LOG}(\mathrm{GDP})+\beta_{2} \mathrm{LOG}(\mathrm{GNI})+\beta_{3} \mathrm{LOG}(\mathrm{GS})+\beta_{4} \mathrm{LOG}(\mathrm{GI})+\beta_{5} \mathrm{LOG}(\mathrm{DIR})+\beta_{6} \mathrm{LOG}(\mathrm{GFI})+\epsilon
$$

Where:

DGI $=$ DSE General Index (All share prices of A, B, G \& N categories of the portfolios of DSE)

GDP $=$ Gross Domestic Product (US\$)

GNI $=$ Gross National Income (US\$)

GS $=$ Gross Savings (US\$)

$\mathrm{GI}=$ Gross Inflation (Inflation, consumer prices annual \%)

DIR $=$ Deposit Interest Rate $(\%)$

GFI $=$ Gross Foreign Investment (Net foreign direct investment, US\$)

$\alpha=$ Total factor of DGI

$\beta$ 's $=$ The respective regression coefficients for GDP, GNI, GS, GI, DIR and GFI, respectively

$\epsilon=$ Random error term (Residual)

To investigate the chronological changes at the time, $t$ on the portfolios of the DSE prices, $Y_{t}$ with respect to the macroeconomic indicators, $\mathrm{X}_{\mathrm{t}}$ 's $\left\{\mathrm{X}_{\mathrm{t}}=\left(\mathrm{GDP}_{\mathrm{t}}, \mathrm{GNI}_{\mathrm{t}}, \mathrm{GS}_{\mathrm{t}}, \mathrm{GI}_{\mathrm{t}}, \mathrm{DIR}_{\mathrm{t}}\right.\right.$, and $\left.\left.\mathrm{GFI}_{\mathrm{t}}\right)\right\}$; ordinary least squares (OLS) minimizes the sum-of-squared residuals obtained from the equation (3) as follows:

$$
\sum \in_{t}^{2}=\sum\left(Y_{t}-X_{t}^{T} \beta\right)^{2}
$$

The first-order conditions for this objective function are obtained by differentiating with respect to $\beta$, yielding

$$
\frac{\partial \sum \epsilon_{t}^{2}}{\partial \beta}=\sum-2\left(Y_{t}-X_{t}^{T} \beta\right) X_{t}
$$

The equation (5) represents the derivatives equation of the portfolios of DSE General Index with respect to the intercept and the coefficients of macroeconomic indicators GDP, GNI, GS, GI, DIR and GFI.

Therefore, the gradient equation at the time, $t$ on the portfolios of DGI with respect to the macroeconomic indicators GDP, GNI, GS, GI, DIR and GFI, respectively is

$g_{t}$ which can be obtained by OLS method as follows:

$$
g_{t}=-2\left(Y_{t}-f_{t}\left(X_{t}, \beta\right)\right)\left(\frac{\partial f_{t}\left(X_{t}, \beta\right)}{\partial \beta}\right)
$$


The estimated regression coefficient of the equation (2) and (3) are tested by Wald's coefficient restriction test as follows:

A general linear regression model is $y=x \beta+\varepsilon$ with respect to the linear restrictions $H_{0}: R \beta-r=0$, where $R$ is a known $q \times k$ matrix, $r$ is a $q$ vector, respectively. Under $H_{0}$, the Wald statistic reduces to

$$
W=(R \beta-r)^{T}\left(R s^{2}\left(x^{T} x\right)^{-1} R^{T}\right)^{-1}(R \beta-r)
$$

which is asymptotically distributed as $\chi^{2}(q)$ under $H_{0}$ and $s^{2}$ is the usual estimator of the unrestricted residual variance.

\section{Analysis and Findings}

\section{Direct Impact on DSE Portfolios}

To investigate the direct and immediate impact on the portfolios of DSE prices Cobb-Douglas functional regression form is used considering the output level STR as dependent variable and the IMC and TEC of DSE as the independent variables. To check existence of multicollinearity between the independent variables IMC and TEC, correlation analysis has been conducted. The result of the correlation analysis is reported in Table 1. There is no multicollinearity problem because none of the correlation coefficient between IMC and TEC is greater than 0.80 .

Table 1

Pearson coefficient of correlation matrix between IMC and TEC

\begin{tabular}{lll}
\hline & IMC & TEC \\
\hline IMC & 1 & 0.275 \\
TEC & 0.275 & 1 \\
\hline
\end{tabular}

The estimation results of Cobb-Douglas functional regression of STR on the independent variables IMC and TEC using the equation (2) is conducted by OLS method which is reported in Table 2.

Table 2

The estimated results of Cobb-Douglas functional regression of STR (Y) on IMC (k) and TEC (L)

\begin{tabular}{lllll}
\hline Variables & Coefficient & Std. Error & t-Statistic & Prob. \\
\hline C & -25.00805 & 3.490276 & -7.165063 & 0.0000 \\
LOG $(\mathrm{k})$ & 0.363238 & 0.160425 & 2.264228 & 0.0348 \\
LOG $(L)$ & 3.842619 & 0.881953 & 4.356942 & 0.0003 \\
R-squared value & 0.775131 & F-statistic & & 34.47036 \\
Log likelihood & -23.34067 & Prob.(F-statistic) & & 0.000000 \\
\hline
\end{tabular}

Dependent Variable: LOG $(Y)$

Sample Range: 1990 to 2012 (Annual)

Data source: http://data.worldbank.org/country/bangladesh

The estimation of Cobb-Douglas functional regression of STR $(Y)$ on $\operatorname{IMC}(k)$ and TEC $(L)$ by OLS gives the following equation: $\mathrm{LOG} Y=-25.00805+3.842619 \mathrm{LOG} L+0.363238 \mathrm{LOG} K$.

The intercept and slope coefficients of all independent variables are statistically significant at least at $5 \%$ level. It is found that total factor turnover ratio, $c=-25.008$ which is negative, therefore there was overall $25 \%$ negative STR due to the fixed cause and the relationship of STR with TEC is positive (3.843) and with IMC is also positive (0.3633) over the period 1990 to 2012. The result is implying that in DSE, a one percent increase TEC then STR also may increase 384.262 percents and a one percent increase IMC then STR also may increase 

Macro Economic Indicators

36.324 percents. Moreover, F-statistic $=90.02$ and Prob. value $=0.00$ imply that the regression model significantly fits the data. Finally, R-squared value indicates that about 77.513 percent variation of STR can be explained by total variations of the independent variables IMC and TEC in DSE. The estimated results of this Cobb-Douglas functional regression of the actual, fitted and residual plot is shown in Figure 1 and the actual, fitted and residual value with residual plot is also shown in Figure 2. From Figure 1 and Figure 2, it is found that in 1991, 2005 and 2006 financial year the fitted values of STR are over the actual value and exceed outside the confidence interval at 5\% level, and in 1998, 1999, 2000 and 2010 financial year the fitted values of STR are under the actual value and exceed outside the confidence interval at 5\% level and in 1990, 1992, 1993, 1994, 1995, 1996, 1997, 2001, 2002, 2003, 2004, 2005, 2006, 2007, 2009, 2011, 2012 financial year the fitted values of STR lie in the confidence interval at $5 \%$ level.

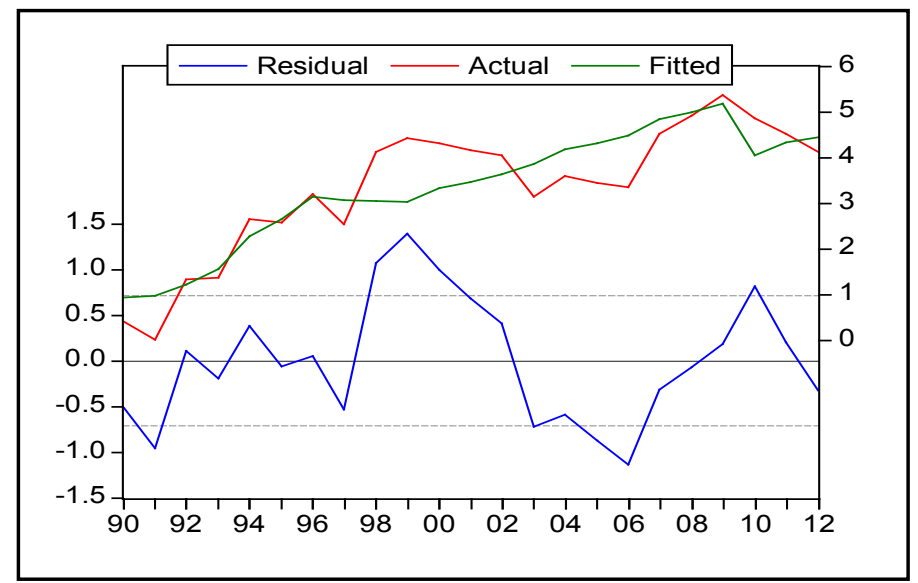

Figure 1. The actual, fitted and residual plot of Cobb-Douglas functional regression of STR on IMC and TEC

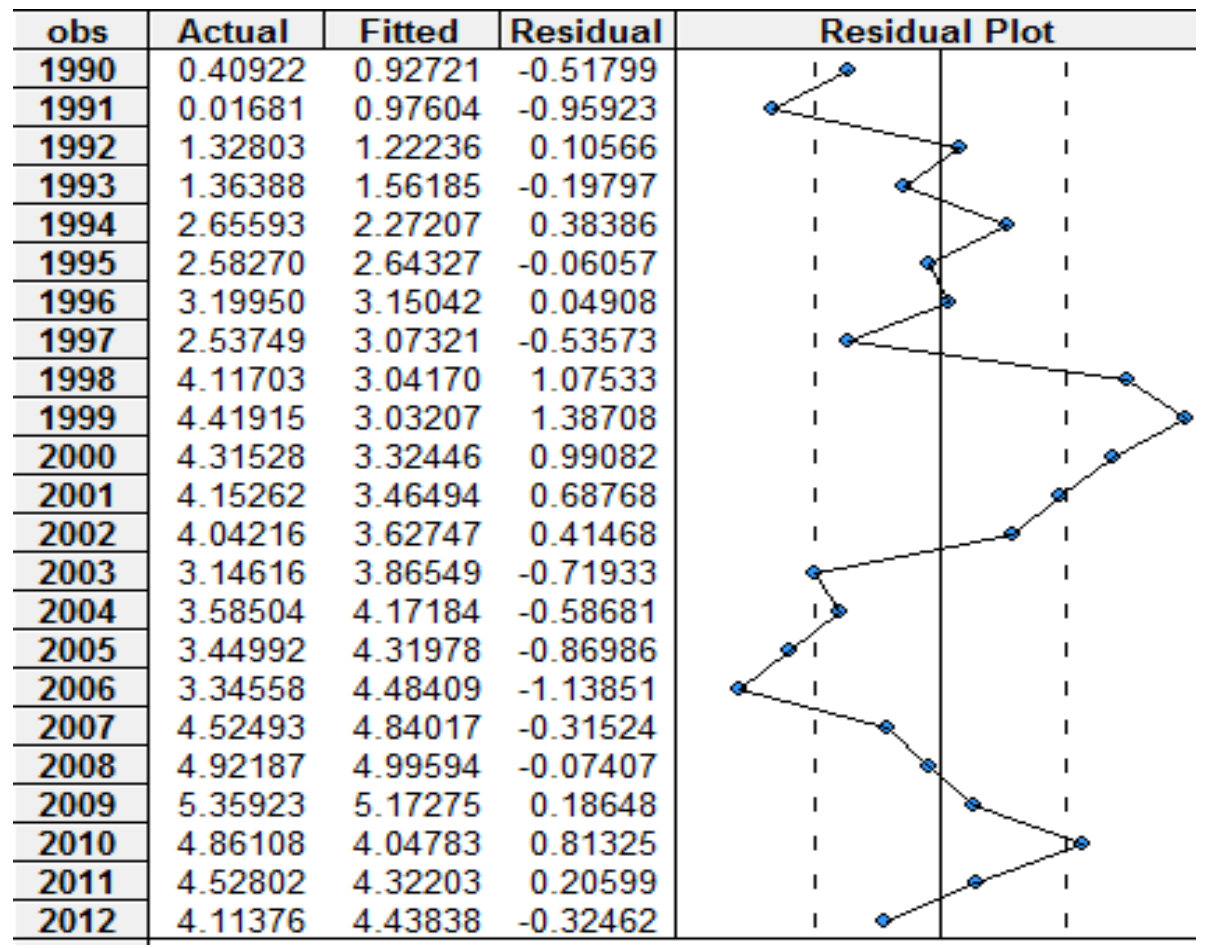

Figure 2. The actual, fitted and residual value of Cobb-Douglas functional regression of STR on IMC and TEC 
The Wald hypothesis of constant returns to scale of the equation (2) is then tested by the equation (7) as the restriction under $\mathrm{H}_{0}: \alpha+\beta=1$ which is reported in Table 3. From Table 3, the null hypothesis is accepted at $1 \%$ level of significant. Hence, the elasticity of STR in DSE with respect to IMC and TEC is constant return to scale.

Table 3

Wald hypothesis test summary of constant returns to scale

\begin{tabular}{llll}
\hline Test Statistic & Value & df & Probability \\
\hline Chi-square & 16.78472 & 1 & 0.0000 \\
Null Hypothesis Summary: & & Value & Std. Err. \\
Normalized Restriction $(=0)$ & & 3.205857 & 0.782505 \\
$-1+\alpha+\beta$ & & \\
Restrictions are linear in coefficients. & & \\
\hline
\end{tabular}

\section{Indirect Impact on DSE Portfolios}

To investigate the indirect and long run impact on the portfolios of DSE prices the multiple log linear regression model is used considering the output level DGI as the dependent variable and the macroeconomic indicators like GDP, GNI, GS, GI, DIR and GFI, respectively as the independent variables. The estimated results of multiple log linear model of DGI on the independent variables GDP, GNI, GS, GI, DIR and GFI, using the equation (3) is conducted by OLS method which is reported in Table 4. From Table 4, it is found that total factor of DGI, $\alpha=-44.936$ which is negative and significant at $5 \%$ level. The coefficients of LOG(GDP), $\mathrm{LOG}(\mathrm{GNI})$ and $\mathrm{LOG}(\mathrm{GFI})$ are significant at $10 \%$ level and the coefficients of $\mathrm{LOG}(\mathrm{GI})$ and $\mathrm{LOG}(\mathrm{DIR})$ are significant at 5\% level and LOG(GS) is insignificant at 10\% level. GDP, GS, GI and GFI have positive impact, and GNI and DIR have the negative impact on DGI. Finally, R-squared value indicates that about 99.9889 percent variation of DGI can be explained by total variations in independent variables GDP, GNI, GS, GI, DIR and GFI, respectively. Moreover, F-statistic $=1502.362$ and Prob. value $=0.0197$ imply that the regression model significantly fits the data at $5 \%$ level.

Table 4

The estimated results of multiple log linear model of DGI on GDP, GNI, GS, GI, DIR and GFI, respectively

\begin{tabular}{lllll}
\hline Variable & Coefficient & Std. Error & t-Statistic & Prob. \\
\hline$\alpha$ & -44.93569 & 1.240996 & -36.20938 & 0.0176 \\
$\beta_{1}$ & 18.18548 & 2.557990 & 7.109285 & 0.0890 \\
$\beta_{2}$ & -19.46508 & 3.050490 & -6.380970 & 0.0990 \\
$\beta_{3}$ & 3.264091 & 0.542459 & 6.017209 & 0.1048 \\
$\beta_{4}$ & 0.753333 & 0.041428 & 18.18422 & 0.0350 \\
$\beta_{5}$ & -1.171250 & 0.050185 & -23.33866 & 0.0273 \\
$\beta_{6}$ & 0.554852 & 0.066922 & 8.290988 & 0.0764 \\
R-squared value & 0.999889 & & & \\
F-statistic & 1502.362 & & & \\
Prob.(F-statistic) & 0.019746 & & & \\
\hline
\end{tabular}

Dependent Variable: LOG(DGI)

Sample Range: 2005 to 2012 (Annual)

Data source: GDP, GNI, GS, GI, DIR and GFI from http://data.worldbank.org/country/bangladesh and DGI from

http://www.dsebd.org/recent_market_information.php 
The estimation of multiple log linear regression of DGI on GDP, GNI, GS, GI, DIR and GFI by OLS gives the following equation: LOG(DGI) $=-44.93569+18.18548 \mathrm{LOG}(\mathrm{GDP})-19.46508 \mathrm{LOG}(\mathrm{GNI})+3.264091$ $\mathrm{LOG}(\mathrm{GS})+0.753333 \mathrm{LOG}(\mathrm{GI})-1.171250 \mathrm{LOG}(\mathrm{DIR})+0.554852 \mathrm{LOG}(\mathrm{GFI})$. The actual, fitted and residual value with residual plot of the equation (3) is shown by Figure-3 which implies that the fitted values are approximately identical the actual value and the estimated residuals lie in the $5 \%$ confidence interval.

\begin{tabular}{|c|c|c|c|c|c|c|}
\hline obs & Actual & Fitted & Residual & \multicolumn{3}{|c|}{ Residual Plot } \\
\hline 2005 & 9.95114 & 9.94646 & 0.00468 & 1 & & 1 \\
\hline 2006 & 9.80890 & 9.82004 & -0.01114 & 1 & & 1 \\
\hline 2007 & 10.1443 & 10.1373 & 0.00700 & 1 & & 1 \\
\hline 2008 & 10.4498 & 10.4486 & 0.00118 & 1 & & 1 \\
\hline 2009 & 10.4407 & 10.4406 & $7.6 \mathrm{E}-05$ & 1 & & । \\
\hline 2010 & 11.2097 & 11.2100 & -0.00028 & 1 & & । \\
\hline 2011 & 11.2168 & 11.2217 & -0.00489 & I & & 1 \\
\hline 2012 & 10.9030 & 10.8996 & 0.00337 & 1 & & 1 \\
\hline
\end{tabular}

Figure 3. The actual, fitted and residual value with residual plot of DGI on GDP, GNI, GS, GI, DIR and GFI, respectively.

The analysis of the magnitudes of derivative of the estimated residual of DGI may give the interesting ideas with respect to the coefficient of GDP, GNI, GS, GI, DIR and GFI, respectively which is reported in Table 5. From the Table 5, it is found that all the magnitudes of derivatives of the estimated residuals are negative and there held the overall downward trend over the period 2005 to 2012 with respect to the intercept and the coefficients of GDP, GNI, GS, GI, DIR and GFI, respectively.

Table 5

Magnitudes of derivative of the estimated residual of DGI with respect to the intercept and the coefficients of GDP, GNI, GS, GI, DIR and GFI, respectively

\begin{tabular}{llllllll}
\hline Year & $\alpha$ & $\beta_{1}$ & $\beta_{2}$ & $\beta_{3}$ & $\beta_{4}$ & $\beta_{5}$ & $\beta_{6}$ \\
\hline 2005 & -1.000 & -24.822 & -24.872 & -23.654 & -1.953 & -2.091 & -20.517 \\
2006 & -1.000 & -24.849 & -24.912 & -23.785 & -1.912 & -2.210 & -20.363 \\
2007 & -1.000 & -24.949 & -25.021 & -23.918 & -2.209 & -2.217 & -20.297 \\
2008 & -1.000 & -25.100 & -25.185 & -24.099 & -2.186 & -2.267 & -20.733 \\
2009 & -1.000 & -25.216 & -25.303 & -24.265 & -1.691 & -2.105 & -20.412 \\
2010 & -1.000 & -25.332 & -25.421 & -24.376 & -2.095 & -1.966 & -20.638 \\
2011 & -1.000 & -25.441 & -25.528 & -24.432 & -2.371 & -2.304 & -20.852 \\
2012 & -1.000 & -25.480 & -25.573 & -24.558 & -1.827 & -2.458 & -20.887 \\
\hline
\end{tabular}

Therefore, the gradients of the objective function which is estimated by the equation (6) at the estimated parameters at $\alpha, \beta_{1}, \beta_{2}, \beta_{3}, \beta_{4}, \beta_{5}$, and $\beta_{6}$ respectively which is shown in Figure 4.

From the Figure 4, there found that the fixed effects of DGI were raised up in 2006 and in 2011 and were raised down in 2007; the effects of GDP, GNI, GS, GI, DIR and GFI were raised up in 2006 and in 2011 and also found that the DGI of DSE was frequently decreasing after 2011 with respect to the fixed cause of DGI and the impact of GDP, GNI, GS, GI, DIR and GFI, respectively on DGI.

The summary statistics of the gradients of DGI with respect to the intercept and the coefficients of GDP, GNI, GS, GI, DIR and GFI, respectively is reported in Table-6.

From Table 6, it reveals that the fixed cause of DGI negatively influence on the share prices and the GDP, GNP, DIR and GFI values positively influence on the share prices of DSE and the GS and GI also negatively influence on the share prices of DSE. 
Econometric Investigation of DSE's Portfolios through Selective Micro and

Macro Economic Indicators
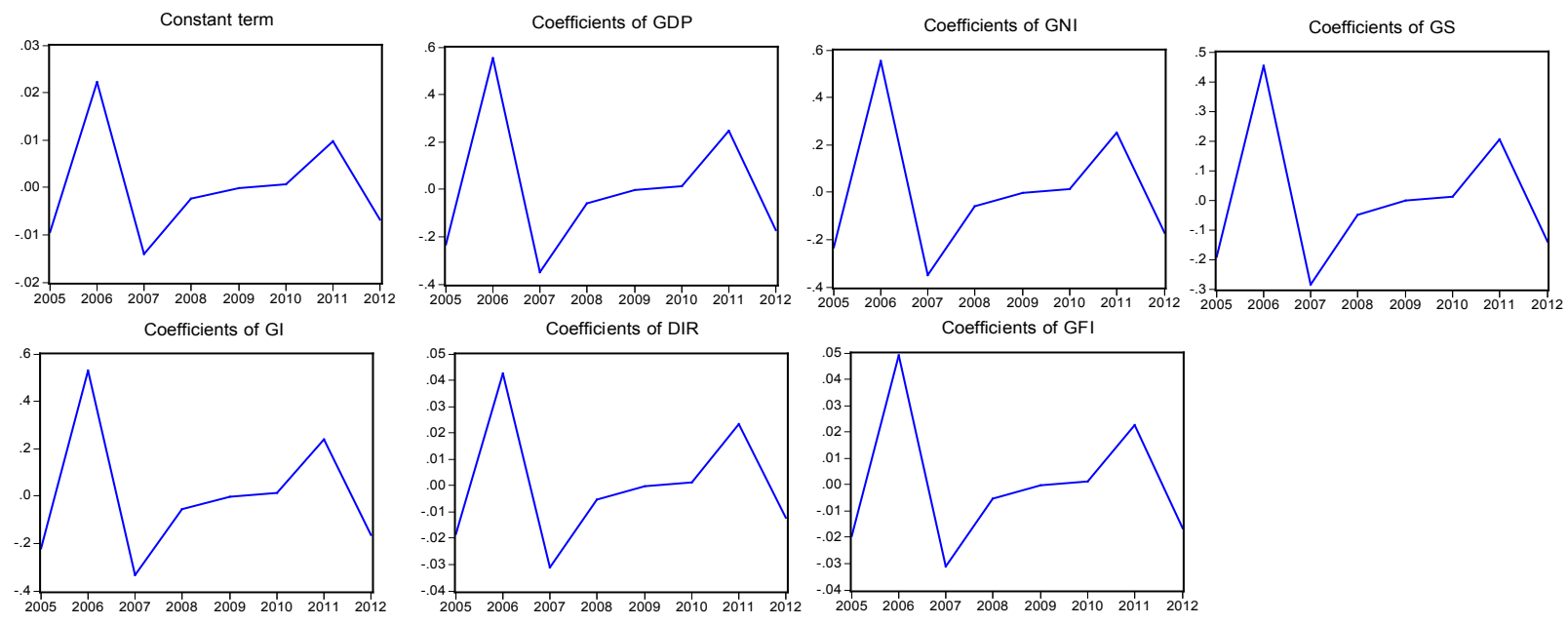

Figure 4. Plot of the gradients of the objective function of DGI with respect to the intercept and the coefficients of GDP, GNI, GS, GI, DIR and GFI, respectively.

Table 6

Summary statistics of the gradients of DGI

\begin{tabular}{lll}
\hline Coefficient & Sum & Mean \\
$\alpha$ & $-8.56 \mathrm{E}-13$ & $-1.07 \mathrm{E}-13$ \\
$\beta_{1}$ & $3.61 \mathrm{E}-12$ & $4.51 \mathrm{E}-13$ \\
$\beta_{2}$ & $5.23 \mathrm{E}-11$ & $6.54 \mathrm{E}-12$ \\
$\beta_{3}$ & $-2.67 \mathrm{E}-11$ & $-3.34 \mathrm{E}-12$ \\
$\beta_{4}$ & $-5.42 \mathrm{E}-13$ & $-6.77 \mathrm{E}-14$ \\
$\beta_{5}$ & $3.25 \mathrm{E}-12$ & $4.06 \mathrm{E}-13$ \\
$\beta_{6}$ & $2.38 \mathrm{E}-11$ & $2.97 \mathrm{E}-12$ \\
\hline
\end{tabular}

\section{Conclusions}

Activities in the stock market can have a profound economic impact on the economy and everyday people. A collapse in share prices has the potential to cause widespread economic disruption. There is no doubt that a vibrant capital market is likely to support economy to be strong but two major catastrophes in the capital market of Bangladesh within one and half decades do not indicate the existence of a vibrant market; rather these show a highly risky and unstable capital market. The overall trend by the estimation of Cobb-Douglas functional regression of Stock Traded Turnover Ratio on Invested Market Capital and Total Enlisted Company of DSE is highly negative and also the estimation of multiple log linear regression of DSE General Index on Gross Domestic Product (US\$), Gross National Income (US\$), Gross Savings (US\$), Gross Inflation (Inflation, consumer prices annual \%), Deposit Interest Rate (\%) and Gross Foreign Investment (Net foreign direct investment, US\$) is also highly negative. Therefore, this study reveals the proof of the surge in the capital market of DSE which has shaken the whole country as millions of people became insolvent within a very short span of time. It was observed in 2010 that the DSE general index was the highest ever which made it Asia's top performer after China (Islam, 2011), while the reverse scenario was scaring investors in the 1st quarter of 2011 as the lowest ever in the index observed during that period. The elasticity of Stock Traded Turnover Ratio in DSE with respect to Invested Market Capital and Total Enlisted Company is constant return to scale. The 
analysis of the magnitudes of derivative of the estimated residual of DSE General Index may give the interesting ideas with respect to the coefficient of GDP, GNI, GS, GI, DIR and GFI, respectively which is found that all the magnitudes of derivatives of the estimated residuals are negative and there holds the overall downward trend over the period 2005 to 2012. This study concludes that for the fixed cause (e.g., artificially manipulating the capital markets by gambling) of DSE General Index negatively influence on the share prices and the Gross Domestic Product (US\$), Gross National Income (US\$), Deposit Interest Rate (\%) and Gross Foreign Investment (Net foreign direct investment, US\$) values positively influence on the share prices of DSE and the Gross Savings (US\$) and Gross Inflation (Inflation, consumer prices annual \%) also negatively influence on the share prices of DSE indirectly in long run.

\section{References}

Akkas, S.M.A. (2011). Review of Bangladesh Capital Market Instability from National Macroeconomic Management Perspective under the global Policy Regimes of Post-Recession Recovery, Economic Research, Vol.12, May 2011 p.81.

Cobb C. W. and Douglas P. H. (1928). A Theory of Production, American Economic Review, 18 (Supplement), 139-165.

Dhaka Stock Exchange (2014). The Dhaka Stock Exchange (DSE) General Index was collected from the websites: http://www.dsebd.org/recent_market_information.php on 20 December 2014.

Fama, E. F. and Schwert, G. W. (1977). Asset Returns and Inflation, Journal of Financial Economics, 5: 115-46.

Hossain, A., Kamruzzaman, M. and Ali, M. A. (2015). ARIMA with GARCH Family Modelling and Projection on Share Volume of DSE, Economics World, Vol. 3, No. 7-8, David Publishing Company, Libertyville, USA, p. 171-184.

Hossain, A., Kamruzzaman, M. and Ali, M. A. (2015). Vector Autoregressive (VAR) Modeling and Projection of DSE, Chinese Business Review, Vol. 14, No. 6, David Publishing Company, Libertyville, USA, p. 273-289.

Islam, M. N. (2011). Problems and Prospects of Stock Market in Bangladesh, Economic Research, Vol.12, May 2011 , p.81.

Mishkin, F. (1977). What Depressed the Consumer? The Household Balance Sheet and the 1973-1975 Recession, Brookings Papers on Economic Activity, 1: 123-164.

Modigliani, F. (1971). Monetary Policy and Consumption: Linkages via Interest Rate and Wealth Effects in the FMP Model, Consumer Spending and Monetary Policy: the Linkages, Federal Reserve Bank of Boston Conference Series, 1971: 5, June1971.

World Bank (2014). The macroeconomic indicators of Bangladesh were collected from the website: http://data.worldbank.org/country/bangladesh on 25 December 2014 